\title{
Linguistic Imperialism and Reshaping the World's New Identity: A Research Paper in Linguistics
}

\author{
Huda Kamal El-qassaby ${ }^{1,2}$ \\ ${ }^{1}$ Linguistics \& Translation, Dammam Girls' Arts College, Dammam, Saudi Arabia \\ ${ }^{2}$ Linguistics, Higher Institute of Languages, Mansura, Egypt
}

Email address:

roaming.star@hotmail.com (H. K. El-qassaby)

\section{To cite this article:}

Huda Kamal El-qassaby. Linguistic Imperialism and Reshaping the World's New Identity: A Research Paper in Linguistics. International Journal of Language and Linguistics. Vol. 3, No. 2, 2015, pp. 61-68. doi: 10.11648/j.ij11.20150302.14

\begin{abstract}
Linguistic imperialism is a controversial issue for its intricate nature and for its impact in a rapidly changing world. English is an imperialist language due to its growing stature in various domains around the world such as: formal education, media, world trade, diplomacy, etc. Hence, English is considered the lingua franca of the modern era, as the most preferred and widely used language in numerous global fields. English emerged as an imperialist language after the decline of minor languages and the dominance of the world imperialism. English as the language of technology and modernization lays its shadows on economics and politics, which affect the social, as well as the cultural identity of the world. English nowadays is significantly related to social and economic rise of people .Apparently, this rise is shown in the constant change of the norms of behavior, values, attitudes and beliefs, particularly among the young generations, as a result of their intensive exposure to English. Certainly, the significant impact of the global dominance of English manifests in constructing social inequalities between those who speak and use English and those who do not. The researcher of this study does not exclude what is called the hidden agenda aimed by the supper powers to reshape the global system through eliminating other cultures and identities and forming new ones. World efforts and procedures are required from scholars, governments and formal institutions to encounter such a phenomenon.
\end{abstract}

Keywords: Linguistic Imperialism, Identity, Global, Dominance

\section{Introduction}

With regard the issue of Linguistic imperialism, some questions are raised: do we really live in the age of linguistic imperialism? Is it a fact or illusion? Does English is a threat to other languages worldwide? Does the spread of English as a global language mean the spread of the western culture? Does the striking dominance of English form cultural and social inequality? Is linguistic imperialism irresistible? Is it a true conspiracy? Is there world effort for an alternative language to be used in all formal contexts allover the world? All these questions need to be answered due to the seriousness of this issue.

First of all, when we consider some definitions of linguistic imperialism as stated by a number of scholars, we should start with Philipson as a pioneer in the field. Phillipson uses the term 'linguistic imperialism', theoretically, to emphasize that languages are hierarchized. By this he means that some languages are widely used than others. Phillipson,(1997:240) uses the term 'linguicism' to pinpoint a biased system, whereby a scheme of linguistic hierarchisation contributes to keeping people in their assigned positions, based on language use. In this sense, 'linguistic power' helps to maintain hegemony .Consider the following definition :

In my usage, linguistic imperialism is a theoretical construct, devised to account for linguistic hierarchisation, to address issues of why some languages come to be used more and others less, what structures and ideologies come to be used more and others less, what structures and ideologies facilitate such processes, and the role of language professionals ... Linguistic imperialism is a subtype of linguicism ... linguicism studies attempt to put the sociology of language and education into a form which furthers scrutiny of how language contributes to unequal access to societal power and how linguistic hierarchies operate and are legitimated. ... Linguistic imperialism takes place within an overarching structure of North/South relations, where language interlocks with other dimensions, cultural (particularly in education, science and the media), economic and political. 
(Phillipson, 1997, pp.238-239)

Knowles explains the transfer of 'dominant languages' to other countries and claims that languages, basically, spread militarily, but nowadays the dominant languages gain support of economic constructs designed to empower them. He also emphasizes that cultures spread along with the languages. Knowles asserts this assumption in the following quote:

... Seen in its simplest terms, language imperialism involves the transfer of a dominant language to other peoples. The transfer is essentially a demonstration of power-traditionally military power, but also in the modern world economic power-and aspects of the dominant culture are usually transferred along with the language. In view of the prestige of the dominant power and its culture, the transfer may not be imposed but actually be demanded by the peoples who adopt the dominant language. It is likely to be regarded as an intrinsically superior language and accorded alleged virtues - e.g., that it is more logical, more beautiful, or easier to learn than the dominated languages. Among the most successful imperial languages are Latin, Arabic, and English. ...

(Knowles, 2001, p. 262 in Encyclopedia Britannica)

In another respect, Crystal (1997) and Phillipson (1992) handle the notion of global English differently. The two scholars differ markedly in their overall treatment of the topic, that English: has become the world's dominant language: Crystal raises some questions about the reasons: why does English spread and take such an incomparable stature over other languages?

It has all happened so quickly. In 1950, any notion of English as a true world language was but a dim, shadowy, theoretical possibility.... Fifty years on, and world English exists as a political and cultural reality. How could such a dramatic linguistic shift has taken place, in less than a lifetime? And why has English, and not some other language, achieved such a status? (Crystal ,1997, P. 1).

Phillipson answers Crystal's questions and stands for the view that the dominance of English as a world language is attributed, in the first place, to the effect of the British empire and the role the English language plays in the teaching profession .

This book explores the contemporary phenomenon of English as a world language and sets out to analyze how the language became so dominant and why ... . whereas once Britannia ruled the waves, now it is English which rules them. The British Empire has given way to the empire of English. This book attempts to contribute to an understanding of the ways in which English prevails. rules, who makes the rules, and what role the English teaching profession plays in promoting the 'rules' of English and the rule of English.

(Philipson, 1992, P. 1)
Obviously, the two scholars agree that English is currently the predominant language worldwide. Crystal and Phillipson pinpoint the concept of power, however the handling of the notion of power-is different. As for Crystal, he assumes that various types of influences, or power-political, military, economic, cultural, among others - best explain why English has become dominant throughout the world. Phillipson, on the other hand, locates power within a larger more expansive concept, that of imperialism. Power, says Phillipson, the power which is expressed in the English language:

In a shocking calculation in early 1990's, current research asserts that the coming century will witness, either the death or the doom of 90 per cent of mankind languages. Krauss (1992) claimed that there would be around 6.000 languages still spoken in the world at the close of the $20^{\text {th }}$ century. The 22 countries that account for around 5.000 of the world's 6.000 languages showing their national official languages and their favored languages in international communication. Consider tables (1-2) in (Graddole, 2002,P. 197).

Table (1). The national official languages in international communication.

\begin{tabular}{|c|c|c|c|}
\hline Country & $\begin{array}{l}\text { Number of } \\
\text { languages }\end{array}$ & National languages & $\begin{array}{l}\text { International } \\
\text { languages }\end{array}$ \\
\hline $\begin{array}{l}\text { Papua new } \\
\text { guinea }\end{array}$ & 850 & English $\backslash$ TokPisin $\backslash$ HiriMotu & English \\
\hline Indonesia & 670 & Bahasa (malay) & English \\
\hline Nigeria & 410 & Englishlyonuba|lboไhausa & English \\
\hline India & 380 & English $\backslash$ Hindi & English \\
\hline Cameroon & 270 & English $\backslash$ French & English $\backslash$ French \\
\hline Australia & 250 & English & English \\
\hline Mexico & 240 & Spanish & English $\backslash$ Spanish \\
\hline Zaire & 210 & French & French \\
\hline Brazil & 210 & Portuguese & $\begin{array}{l}\text { English } \\
\text { Portuguese }\end{array}$ \\
\hline
\end{tabular}

Table (2). Countries each accounts for 100 -160 languages .

\begin{tabular}{lll}
\hline Philipines & English $\backslash$ philipino & English \\
\hline Former Ussr & Russian & Russian\English \\
USA & English & English \\
Malaysia & Bahasa $\backslash$ Malysia & English \\
China & Putonghua(mandarin) & English \\
Sudan & Arabic & English \\
Tanzania & Swahili\English & English \\
Ethiopia & Amharic $\backslash$ English & English \\
Chad & French $\backslash$ Arabic & French \\
Nepal & Nepali & English \\
\hline
\end{tabular}

Thus, English as an imperialist language has become a settled fact, particularly in the world of communication, governmental and educational institutions, world trade and diplomacy, etc. So developing countries and the nations with lesser used languages should be aware of the expected threat of English language, as it reshapes, not only other nations' cultures, but also eliminates some others. Actually, the issue of the extinction of minor languages as a result of the dominance of English that swallows them has been raised in the council of 1988 Europe's Charter for Regional and Minority Languages (1988). In this council, there was an emphasis on a multilingual context and support for minority languages. In a similar respect, within the United Nations, the universal 
Declaration of Linguistic Rights, the right of all people to develop and promote their mother languages has been emphasized. (Brown,2007,p.206).Consider table (3) which shows the dominance of English worldwide.

Table (3). Major world languages in millions of first-language speakers according to the Engco Model and comparative figure from Ethnologue.

\begin{tabular}{llll}
\hline & Language & EngcoModel & Ethnologue \\
\hline 1 & Chinese & 1,123 & 1.113 \\
2 & English & 322 & 372 \\
3 & Hindi/Urdu & 236 & 316 \\
4 & Spanish & 266 & 304 \\
5 & Arabic & 202 & 201 \\
6 & Portuguese & 170 & 165 \\
7 & Russian & 288 & 155 \\
8 & Bengali & 189 & 125 \\
9 & Japanese & 125 & 123 \\
10 & German & 98 & 102 \\
11 & French & 72 & 70 \\
12 & Italian & 63 & 57 \\
13 & Malay & 47 & 47 \\
\hline
\end{tabular}

(Grimes (1996) in Zughoul, 2003)

According to a press release from the British Council, it has been indicated that the English language almost prevails allover the world to become a global language of the twenty one century in most of the official and crucial fields of modern life. This fact is asserted in the following shocking statistic:

Worldwide, there are over 1,400 million people living in countries where English has status. One out of five of the world's population speaks English to some level of competence. Demand from the other four-fifths is increasing...By the year 2000, it is estimated that one over billion people will be learning English. English is the main language of books, newspapers, airports and air, traffic control, international business, academic conference, science and technology, diplomacy, sport, etc.

(British Council, English 2000 press release, 23 March, (Graddole, 2002, p.181)

As English is dominant in most international corporations, as well as in bodies such as the United Nations and the World Trade Organization, English is usually accepted as a global language of communication. English has; therefore become the language of diplomacy and is thus the "established lingua franca of the political sphere, because it is the language of the most powerful players and of the dominating ideology". (Wright, 2004, p, 150). Because communication with all participants in a globalized world is indispensable and English has become a fact and an uncompetitive medium, we can definitely assert that communicative imperialism is bolstered every day through linguistic imperialism. See the following chart which shows the expansion of English speakers worldwide.

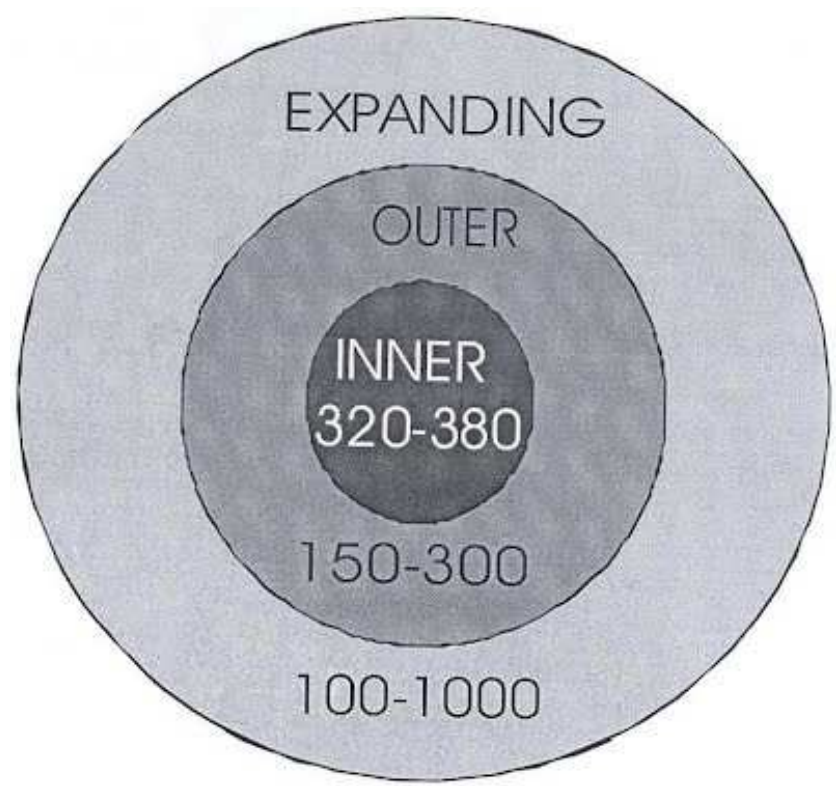

Chart (1). Kachru's Three Circles of English Speakers.

(Crystal (1997) in Zughoul, 2003)

Certainly, the danger is not included only in such a rapid flow of English everywhere, but the real danger lies in the dominance of the English mentality which is imported into every part of the world through the spread of technological and electronic devices, and through the film industry which entails the western culture with all its aspects. When we have a look at how the adults behave, eat, dress, and think, we realize the impact of such a phenomenon. Therefore, it becomes apparent that cultural imperialism is a settled and inevitable fact. (Scollen, 2004).

In another respect, Eco, a well- known Italian novelist and cultural theorist, adds other reasons for the spread and dominance of English over other languages. He asserts that the rapid and unavoidable spread of English Language over other languages worldwide is attributed, not only to the colonial expansion of the British empire, but also to the nature and structure of English which makes it capable of absorbing foreign languages and forming neologism.

The predominant position currently enjoyed by English is a historical contingency arising from the mercantile and colonial expansion of the British empire, which was followed by American economic and technological hegemony. Of course, it may also be manipulated that English has succeeded because it is rich in monosyllables, capable of absorbing foreign words and flexible in forming neologism

(Eco,1995, p.331)

\section{Why English and not Other Languages}

The dominance of English has raised the most exciting debates on language policy nowadays. The basic questions are: Why English and not other languages? How did English prevail externally and internally to become the major world language? Who, if anyone, is responsible for this striking 
phenomenon of the global spread of English? Will English continue to occupy its stature. How did English develop from being one of the few powerful international colonial languages, to the position of the hegemonic world language?(Hamel, 2006). Most of the debate on these topics occurs within the Anglo-Saxon world itself, with a salient participation of British (Crystal 1997, Graddol 1997, and Phillipson, 1992) and British colonial authors (Kachru 1991, Pattanayak 1996, andKhubchandani 1997).

Crystal (1997) claims that in 1950, world English was still not a major issue. In retrospect, however, it becomes obvious that the future of English was deeply rooted in the British pattern of migration-intensive colonization of North America, and the building of its colonial empire in Africa and Asia. When economic and political leadership moved from Britain to the USA in the early 20th century, English, along with other factors of shared culture, was the normal channel between the old and the new empire that based the rules of the game and allowed English to dominate over its competitors. Crystal concludes that English is "a language which has repeatedly found itself in the right place at the right time" (1997, p. 110).

Hamel (2006) raises important questions about the factors which contribute to make a certain language prevails and dominates. He assumes that there are various reasons of the phenomenon of linguistic imperialism. He claims that the spread of English is due to language shift, dominance or linguicism, but he adds other factors such as: economic, cultural and political processes which contribute to the building of empires, that is, to their stability, reign, and governance over linguistically diverse, multicultural populations. And, in what ways do empires create imperial languages or, to put it conversely, to what extent do linguistic constellations develop with a certain autonomy from the economic, political and cultural processes that might have brought them about in the first place? These are other questions raised by (Hamel, 2006:5). From the perspective of a political sociology of language, De Swaan asserts that the spread of English language, is it for military, religious or economic expansion or for other factors?

whether the processes of language spread and language decline reveal a dynamics of their own, or rather are completely determined by other processes, such as military conquest, religious, $\{\ldots\}$ commercial expansion. In the latter case the language system is an epiphenomenon, of descriptive interest certainly, but devoid of explanation.

(DeSwaan, 1993, p.221)

Another basic reason for the dominance of English as a world language is that English is looked upon as a mean to get economic opportunities, improve standard of living, gain social status and public recognition. That is why we notice that important posts and positions are promised to those who speak English fluently. Apparently, many families invest in educating their children in international schools and at reputable universities to help them get unique positions and bright careers, as they are promised by linguistic imperialism.
Within the impetus and overwhelming impact of English, the native culture and identity, gradually and unconsciously occupy lesser status by time among individuals and groups.

\section{Linguistic Imperialism: Is it a True Conspiracy}

The concept of linguistic imperialism and the dominance of English as a conspiracy intended by imperial powers to achieve secret political and economic agendas is broadly discussed in Spolsky's book Language Policy (2004) and in Phillipson's Linguistic imperialism (1992).It is assumed that the policies intended by political and economic powers may draw the attention away from hidden policies and goals and from the reality of how dominance and inequality are intended and legitimated. The promotion of English in broader political and economic activities is well accounted. Language policy and management require more insightful and thorough efforts, drawing on a wider knowledge to justify whether linguistic imperialism is a conspiracy or rather a conspiracy of silence as assumed by Philipson (1992).

Considering the multiplicity and complexity of the social, economic and political conditions helps to gain more insight into the issue, in order to identify its causes and consequences well. In the researcher's point of view, in such an intricate world with its interrelated interests and covert policies, it becomes hard to either predict or confirm the outcome of such phenomenon. Spolsky (2004) argues : "... that my analysis of the global dominance of English" . (p.79) does not see it as a complex result of a multitude of factors. but as due to a conspiracy. However, a conspiracy theory is often the standard in validating predicate to block tracking of strategic decisions."

McMurtry, stands with those who believe in conspiracy theory and claims that as, a philosopher, he is rather interested in the deeper question of the life and death principles of regulating value systems which connect across and explain social orders.(McMurtry, 2002: 17 xiv).It is; therefore stated that a conspiracy theory is inadequate as a mean of grasping the role of the key actors in center or Periphery. The conspiracy explanation tends to be too vague and undifferentiated to merit being called a theory. It also ignores the structure within which the actors operate. (Phillipson, 1992, p. 63).

In treatment of this issue, Stiglitz in his insider denunciation of how the World Bank operates argues that globalization has a devastating impact on developing countries as policies and decisions are made just to fit the interests of the people in power, not taking into consideration, neither the benefit nor the interests of developing nations, particularly the poor ones. Consider the following assumption:

I have written this book because while I was at the World Bank, I saw, first the devastating effect that globalization can have on developing countries, and especially the poor within those countries, decisions were often made because of ideology and politics. As a result, many wrong-headed actions 
were taken, ones that did not solve the problem at hand but that fit with the interests and beliefs of the people in power. Academics involved in making policy recommendations become politicized and start to bend the evidence to fit the ideas of those in charge. There are no smoking here. You want to find evidence here of a terrible conspiracy by Wall Street and the IMF to take over the world. I do not believe such a conspiracy exists. The truth is subtler. Often in a tone of voice, or a meeting behind closed doors, or a memo that determines the outcome of discussions.(Stiglitz, 2002, ix-x, Xv).

In reality, it is inconceivable that any language can spread, due to other factors other than just military, economic, religious, etc. Phillipson (1992) emphasizes the role played by linguistic imperialism within a wider imperial, or exploitative structure. Spolsky (2004) sees the vulnerability or demise of powerless languages as a natural progress, the alternative to which is implementation of some conscious policy on the part of governments, civil servants, English-teaching professionals and their elite collaborators and successors in the peripheral countries. (op.cit., 79).

As for Spolsky (2004), he maintains that the causal factor was imperialism rather than linguistic imperialism (ibid., 85). Drawing on work by Fishman and De Swaan, it is concluded that the global dominance of English is due to the changing nature of the World English being widespread, and because the remaining superpower used it unconsciously. (ibid. 88). So that English was merely there for the taking (although he puzzlingly restricts this to international communication, this apparently not affecting what happens within countries).

Curtis (2004), in a striking debate argues that the underlying agendas of British foreign policy aim at the promotion of English language. In this regard, Curtis explored three conclusions: (1) the culture of lying and misleading the electorate is deeply embedded in British policy-making; 2) In contrast, the covert record of official files is quite open about goals that differ markedly from what is made public. Curtis considers this as evidence not of a conscious conspiracy, but rather that foreign-policy making is confidential, elitist and unaccountable that policy-makers know they can get away with. This idea is mentioned in Curtis' third conclusion:

...almost anything. 3) humanitarian interests do not figure at all in the rationale behind British foreign policy. Tony Blair is lying about the Iraq war provides a vivid example of these three, in tandem with similar attitude by George W. Bush. American goals have been explicit and consistent since World War II. In 1948, the State Department's senior imperial planner, George Kennan, wrote: We have 50per cent of the world's wealth, but only 6.3 per cent of its population. In this situation, our real job in the forthcoming period is to devise a pattern of relationships which allow us to maintain this position of disparity. To do so, we have to dispense with all sentimentality. We should cease thinking about human rights, the raising of living standards and democratization.(quoted in Pilger, 1998, p. 59).

In praise of cultural imperialism, in Foreign policy, by David Rothkopf, Director of the Kissinger Institute, in 1997: he claims that Language policy is essential to this mission. It is in the agenda of the economic and political interest of the United States is to ensure that if the world is moving towards a common language, common, telecommunications, safety, and quality standards and that if common values are being developed. These are not idle aspirations. English is linking the world.

Actually, we need studies that can reveal the world underlying policy with its complicities, covert activities and interrelated interests. Governments of powerless languages and less economic and political status should set strategic goals and means in order to share in the game, and in order to get a deeper understanding of how language policy fits into and constitutes the wider picture. (Canagarajah, 1999).

\section{World Effort and Language Planning}

In an attempt to reduce the dominant effect of the spread of English which represents a threat to other cultures and languages, the French Canadians exert great effort to encounter the English language impact on their 'French' culture. To elaborate; the province of Québec, Canada has elected to remain out of the Canadian constitution which emphasizes that all provinces in Canada are forced to support French-English bilingualism in an attempt to hold onto the use of the French language in all domains. Unlike the rest of Canada, French is the only official language in Quebec and store signs must be in French with English only permitted in small print. Even the stop signs read 'ARRET' (stop in French), while in France all stop signs read 'STOP'. Also, children of newly arrived immigrants to Canada are legally required to attend French language schools. (Corrigan, 2006).

In a similar respect, other governments allover the word, i.e., China and France have introduced legislations in way of language planning that require TV and Radio stations to play mainly native content, thus, restricting access to English language programs (Kennedy, et al 2001:76 \& China 'bans primetime Simpsons' BBC Online News). Almost a considerable number of governments fight hard to prevent English from swallowing their respective native languages by way of 'language shift'. Actually, they are countering the effects of English Language imperialism.

\section{Impact of Language Shift}

Language shift happens when a foreign language gradually overwhelms the native tongue of other countries throughout the course of time. It has been stated that EIL is becoming widely adopted by people who speak it as a second language, for personal and social reasons and not as something being imposed from external ways. Swales (1993) emphasized that:"...internationalism favors no nation nor gives any permanent credit for the length of membership in a global association. Therefore, we have to concede that it no longer makes any sense to differentiate between the native speaker and the non-native speaker"(p.284). In a similar respect Walker (2001,p. 1) states that there are now more exchanges between non-native speakers of English than between 
non-native speakers and native speakers.

According to Holmes (2001:.52), when 'language shift' occurs, a society unwillingly and unconsciously gives up its identity and finds itself dragged into a new one, as part of the new language and cultural concepts associated to it. By time, and under the impact of incoming language and culture, the identity of the native language gradually evaporates and hides behind the new one, particularly if not met with efforts to reduce or prevent its effect on society and individuals.

Moreover, language shift is a direct result of political and economic impetus, i.e., learning, the incoming language as previously mentioned, is associated with work. People in the developing countries are ready, not only to shift their language, but also to shift their residence, as a result of the deterioration of economic and social conditions. To elaborate, we notice that people emigrate to western countries, either for the purpose of study or for the purpose of looking for better job opportunities. In both cases, the danger exists. Those migrants find themselves surrounded by foreign language, and foreign culture. Of course, the faster those people adopt the foreign culture, the more their conditions improve, consequently and gradually their native language and culture evade.

Naturally, language shift takes place in one direction with the minority group's language being taken over by that of the dominant majority group (Holmes, 2001,p. 56). Accordingly, the majority language has the tendency to show glamorous norms which many minority language speakers find simply irresistible. (Holmes, p.55). For instance, English is the dominant language of popular music, movie industry, fashion that young people admire and cannot resist. In fact, this assumption further fosters and supports the claim that English is hegemonic and hence that English is imperialist.

In truth, the expansion in the international use of English serves as a sizeable benefit, in all fields - economics, commercials, media, politics, etc. Maurais, et al (2003). This expansion has been stressed in widespread global change which manifested in the emergence of regional economic blocs and political unions. States in Europe and on other parts of the world have realized that competing successfully in the new world requires them to rise their political-economic weight and/or their geostrategic influence. That is why new regional agreements and treaties have sprung up, creating organizations like the European Union, NAFTA and Mercosur. Involvement in the new world system makes impossible to resist or prevent the impact of changing or reshaping social identity too.

In Europe, for instance, there is fear of US cultural imperialism. It may be felt even clearly in Canada, which is geographically much closer and, for the most part, shares English as a language of family life and daily use, as Canada has. differentiated identity. Mahant, et al (2001,pp. 449-465).

Thus, it could be reasonable to emphasize that English is very adaptable and thus is likely to be a sustaining phenomenon capable of swallowing other language. Also, it exceeded its traditional functions to introduce extra possibilities for its users to be used in a wide range.
Language shift has an impact on many countries. In Mexico, for instance, voices of concern can also be heard, citing the danger of "Americanization" from the United States, especially in light of the cross-border contacts between the two countries and the scope of their interactions. Because English is spreading in Mexico as an L2 or "foreign" language", there is an unease over the issues of identity which always come to surface. For example, as Schmid (2001) points out: "Unfortunately, education in the United States strongly encourages immigrant children to lose their fluency in the languages they speak at home. This policy is in agreement with the languages they speak at home. This policy is in agreement with nativist ideals and organizations such as U.S. English (...), but is at odds with the interests of individuals and a global economy" (p. 9).

\section{English and the Formation of Social Inequality}

As previously explained, scholars draw the attention to the potential consequences of English teaching and practice worldwide and its expected colonial effect in constructing power and dominance. The most obvious effect of linguistic imperialism does not only entail power and dominance over other languages, but most importantly it plays a crucial role in the establishment of "social inequalities between the speakers of English and the speakers of other languages" (Philipson, 1992:47).

When we consider the world map in which English is used as a second language, along with the increasing expansion of the foreign universities and educational institutions, particularly in the Arab and Islamic world, we realize that the challenge is great and the threat is greater. The main danger, undoubtedly, is the expected destruction of global ecology of native languages and cultures, particularly because English is related to economic prosperity and distinguished social status. On the other side, the native languages are out of concern and do not exceed being a mean of every day communication.

Actually, the major concern behind raising the issue of the overwhelming spread of English aims, not only to discuss the threat of devastating the native languages, but also to ring the bell of danger of imposing foreign values on those who intensively learn and speak it. Also, the formation of social inequality among the speakers of English results, not only in reshaping social identity, but also in the extinction of cultural identity as well. In the researcher's point of view, the real danger of linguistic imperialism does not lie in the threat of eliminating other languages, but mainly in the exclusion of cultural and social identities of individuals and nations.

The dominance of English in almost all crucial fields, particularly in education has an undeniable impact on adults who can be easily touched by the western culture which is implemented in the English curricula they study, particularly many of the hidden cultural concepts inserted throughout Foreign curricula are not met with social awareness on the part of learners and tutors, or on the level of governmental and 
educational institution. From a long experience in teaching English in foreign educational institutions, it has been noticed that students who expose more to English behave in a totally different manner and stand for different ideas, which reflect the effect of the foreign culture on their norms of behavior, beliefs and attitudes towards their original culture and identity. This generation is an outcome of the western culture that overwhelms them, whether consciously or unconsciously. Consequently, there is a crucial need, particularly in the Arab and Islamic world to confront the danger of linguistic imperialism, which threatens the social, religious and cultural values in these societies.

\section{Linguistic Imperialism and Multiethnicity}

Another effect of linguistic imperialism is emphasized in the increasing multiethnicity and social tensions, due to the significant growth in migration. A vast number of individuals have left their territories of origin for other more economically developed societies, seeking greater prosperity for themselves and for their families. According to the UN's Population Division, in 2010 there were an estimate of 213.9 million immigrants worldwide compared to 155.5 in 1990.54 The majority of the immigrant population goes to developed countries, which currently receive $59.7 \%$ of the total as against 53\% in 1990.55.(Cohen,1999).

Actually, Many foreign countries always welcome immigrants and facilitate their integration in the western society. Some of the receiving countries tend to set strict rules to control the effect of immigrants' culture, so those immigrants find themselves obliged to be quickly immersed in the new culture of the receiving countries, meanwhile they neglect and forget their original identity and culture gradually under the impact of the new culture .

Undoubtedly, there is a sort of interrelatedness between adopting English and the reformation of identities. English as a medium of communication serves, in the beginning, as a quick and easy way to interact, can later become, on basis of identity, a source of resentment towards the immigrants on the part of the receiving population, especially if immigrants are numerous. Given that language acts not only as a code for communication but is also bound up with identity. (See McAndrew, 2010).

Consequently, receiving populations will also have to undergo an adaptation of identity, changing their conception from one of a uniform culture to a diverse culture, made up of people from various places of origin, who are fully accepted and socioeconomically integrated. (Wright, 2004,p.10).

In the global era, English language has become a common vehicle of interaction and of shared civic and political identity. Thus, the defense of language and identity has risen as never before, particularly as regards the spread of English as the language of global relations, but also with respect to the new political and economic unions that cross individual state borders.
Thus, the horror over identity aroused through globalization, and its association with language, rests basically on the dual social function of language, namely communication and identification (or identity-building). Although language clearly serves as a vehicle for communication, in other words, for inter-signification, it also provides key elements of broad discussion and conclusions .(Scollen, 2004).

Certainly, the social and cultural impact of the spread of EFL has become an established fact. However, they are less significant, if compared to the serious consequences created by the economic considerations, which are mainly responsible for creating social inequality. The flow of EIL from the center to the periphery, thus, has a damaging and unpredictable influence on the countries that use it. Of course this effect is noticeable in the destruction of minority languages and the elimination of their culture. (Finch, 2000).

Moreover, the impact of technology which is closely related to the spread of EFL, also plays a crucial role in the destruction of social and cultural identity .This assumption is emphasized by Abbott (1992) "The widely perceived need to promote technological development through teaching an international language such as English overshadows an arguably more basic need to transmit indigenous cultures". (P.174). Friere (1972) calls this 'cultural invasion'. (P.121). In India, for example, the overwhelming impact of English on all the aspects of life reflects the suppression of the native culture and thought .Tully (1997:157) asserts that English in India for instance is " ...not just an unhealthy hangover after colonialism, but also a means of continuing the suppression of Indian thought, and of preserving an alien, elite culture". It is generally assumed that more social and economic divisions and the marginalizing of minority cultures, languages, religions and ethnic groups are expected as a result of linguistic imperialism that spreads widely and quickly, whether resisted or not.

\section{Conclusion}

Apparently, the English language is almost the sole language of the new glob. Although, one thing for sure is that no one can deny its benefits, socially and economically. Also, no one can prevent or ignore its serious impact on reshaping people's social and cultural identity. Besides, it is confirmed that the global spread of English does not only result in creating equality among individuals of the same community, but also represents a threat of the lesser native languages worldwide. Consequently, it is difficult to deny the development of a Global Linguistic Empire and, thus the status of English as an imperialist language.

In the researcher's opinion, English is imperialist, as a result of its hegemony and inner circle influence. Also, because it is penetrating increasingly into more domains globally, and whether it is adopted willingly or unwillingly. Apparently and undoubtedly, English as a world language, does not only sweep other lesser used languages, but also reshapes the new world's economic, politicalstructure and constructs new social identities. In spite of the researches conducted by linguists and 
scholars, linguistic imperialism as a controversial issue has not been settled yet. Whether linguistic imperialism is a fact or an illusion, whether it is a true conspiracy or just a world phenomenon among various phenomena, there is a crucial need for more efforts from linguists and socialists to investigate this issue, in order to introduce decisive views with regard to this intricate and crucial issue.

\section{References}

[1] Abbott, G. (1992) .Development, Education, and English language Teaching. ELT Journal 46/2: 172-178.

[2] Brown, D. (2007). Principles of Language Learning and Teaching. Pearson Education, San Francisco State University.

[3] Canagarajah, A.(1999). Resisting Linguistic Imperialism. Oxford: Oxford University Press.

[4] Cohen, Robin. (1999).The Making of Ethnicity: A modest defense of primordialism in: Mortimer, Edward (ed.). People, Nation \& State. The Meaning of Ethnicity \& Nationalism. London/New York: I.B. Tauris Publ, pp. 3-11.

[5] Corrigan, P. (2006).French-only laws Hurt Canadian life. The State News, October $4^{\text {th }}, 2000$ [Online] Available at: (Accessed August 10, 2006).

[6] Curtis, Mark (2004). Unpeople: Britain's Secret Human Rights Abuses. London: Vintage.

[7] Crystal, D. (1997). English as a Global Language. Cambridge: Cambridge University Press.

[8] De Swaan, A. (1993). The Emergent World Language System: An introduction in: International Political Science Review, 14, 3, 219-226.

[9] De Swaan, A.(2005).Words of the World: The global language System. Cambridge, Polity Press.

[10] Eco, U.(1995). The Search for the Perfect Language, Oxford, Blackwell.

[11] Finch, A. E. (2000).A Formative Evaluation of Task-Based EFL Program for Korean University Students; Chapter 2 'The Situation', Section 2.4.3, Unpublished PHD. Thesis, Manchester University, U.K. [Online] (Accessed).

[12] Friere, P. (1972).Pedagogy of the Oppressed. Harmondsworth: Penguin Books Ltd.

[13] Graddole, D. and Goodman, S. (2002).Redesigning English: New texts, new identities, Rutledge.

[14] Hamel, R.E. (2006). The Development of Language Empire. In Ammon Urich.

[15] Holmes, J. (2001).An Introduction to Sociolinguistics, Second Edition, Longman, Harlow.

[16] Kachrue, B.B. (1991). World Englishes and Applied Linguistics, in Tickoo, M.l (ed.). Languages and Standards: issues, attitudes, case studies, Anthology 26, Singapore, SEAMEO, Regional Language Centre.

[17] Krauss, N. (1992).The world's Language in Crisis. Language. Vol.68, no.1.
[18] Kennedy, C., Knowles, M., Caldas-Coulthard, C. R., Coulthard, M. (2001).Sociolinguistics, The University of Birmingham, Centre for English Language Studies, Department of English, Birmingham.

[19] Khubchandani, Lachman (1997). Revisualising boundaries. A plurilingualethos, New Delhi/Thousand Oaks: Sage.

[20] Mahant, Edelgard E. \& Graeme S. Mount. (2001) .The U.S. Cultural Impact upon Canada. American Review of Canadian Studies. 31: 449-465.

[21] Maurais, Jacques, \& Michael A. Morris.(2003).Languages in a Globalising World. Cambridge: Cambridge University Press.

[22] McAndrew, Marie.(2010).Les majoritésfragilesetl'éducation. Montréal: Les Presses de l'Université de Montréal,.

[23] McMurtry, John.(2002). Value wars. The Global Market Versus the Life Economy. London: Pluto.

[24] Pattanayak, D.(1996). Change Language and Developing World, in Coleman H. and Cameron, L. (eds) Change and Language, Clevedon, BAAL, Multilingual Matters.

[25] Pilger, John .( 1998). Hidden Agendas. London: Vintage.

[26] Phillipson, R. ((1992). Linguistic Imperialism. Oxford, Oxford University Press.

[27] Phillipson, R. (1997).Realities and Myths of Linguistic Imperialism, Journal of Multilingual and Multicultural Development,18/3,p.248.

[28] Rothkopf, David. (1997). In Phillipson, R. (1997).Linguistic Imperialism. Oxford University Press.

[29] Schmid, Carol L. (2001). The politics of language. Conflict, identity and cultural pluralism in comparative perspective. Oxford: Oxford University Press.

[30] Scollen, R. (2004). Teaching Language and Culture as Hegemonic Practice. Modern Language Journal,88,271-274.

[31] Spolsky, B.( 2004).Language Policy. Cambridge: Cambridge University Press.

[32] Stiglitz, J.( 2002). Globalization and its Discontents. London, Penguin.

[33] Swales, J. (1993) .The English Language and its Teachers' thoughts: past, and present. Cambridge: Cambridge University Press.

[34] Tully, M. (1997) .English: an advantage to India? ELT Journal 51/2: 157-164.

[35] Walker, R. (2001).International Intelligibility. English Teaching Professional, Issue 21, October.

[36] Wright, R. (2004). Stolen Continents: 500 Years of Conquest and Resistancein the Americas. Boston: Houghton Mifflin Company.

[37] Wright, Sue(2004).Language Policy and language planning. From nationalism toglobalization. Houndmills, Basingstoke, Hampshire: Palgrave McMillan.

[38] Zughoul, M.R. (2003).Globalization and EFL/ESL Pedagogy in the Arab World. Yarmik University, Jordan Journal of Language and Learning, Volume 1, Number 2,(Accessed on August 2, 2006). 